\title{
Quantitative risk assessment of continuous liquid spill fires based on spread and burning behaviours
}

Zhao, Jinlong; Huang, Hong; Li, Yuntao; Jomaas, Grunde; Wang, Haiyan; Zhong, Maohua

Published in:

Applied Thermal Engineering

Link to article, DOI:

10.1016/j.applthermaleng.2017.07.187

Publication date:

2017

Document Version

Peer reviewed version

Link back to DTU Orbit

Citation (APA):

Zhao, J., Huang, H., Li, Y., Jomaas, G., Wang, H., \& Zhong, M. (2017). Quantitative risk assessment of continuous liquid spill fires based on spread and burning behaviours. Applied Thermal Engineering, 126, 500506. https://doi.org/10.1016/j.applthermaleng.2017.07.187

\section{General rights}

Copyright and moral rights for the publications made accessible in the public portal are retained by the authors and/or other copyright owners and it is a condition of accessing publications that users recognise and abide by the legal requirements associated with these rights.

- Users may download and print one copy of any publication from the public portal for the purpose of private study or research.

- You may not further distribute the material or use it for any profit-making activity or commercial gain

- You may freely distribute the URL identifying the publication in the public portal 


\title{
Quantitative risk assessment of continuous liquid spill fires based on spread and burning behaviours
}

\author{
Jinlong Zhao ${ }^{1,2}$, Hong Huang1*, Yuntao Li³, Grunde Jomaas², 4 , \\ Haiyan Wang ${ }^{5}$ Maohua Zhong ${ }^{1}$
}

${ }^{1}$ Institute of Public Safety Research, Department of Engineering Physics, Tsinghua University, Beijing,

China

${ }^{2}$ Department of Civil Engineering, Technical University of Denmark, Kgs. Lyngby, Denmark

${ }^{3}$ School of Mechanical and Transportation Engineering, China University of Petroleum, Beijing, China

${ }^{4}$ BRE Centre for Fire Safety Engineering, University of Edinburgh, Edinburgh, UK

${ }^{5}$ Faculty of Resources \& Safety Engineering, China University of Mining \& Technology, Beijing, China

Abstract: Spill fires usually occur during the storage and transportation of hazardous materials, posing a threat to the people and environment in their immediate proximity. In this paper, a classical Quantitative Risk Assessment (QRA) method is used to assess the risk of spill fires. In this method, the maximum spread area and the steady burning area are introduced as parameters to clearly assess the range of influence of the spill fire. In the calculations, a modified spread model that takes into consideration the burning rate variation is established to calculate the maximum spread area. Furthermore, the steady burning area is calculated based on volume conservation between the leakage rate and the fuel consumption rate due to burning. Combining these two parameters with leakage frequency, flame model, and vulnerability model, 
the dynamic individual risk can be calculated quantitatively. Subsequently, large-scale experiments of spill fires on water and a glass sheet were conducted to verify the accuracy and application of the model. The results show that the procedure we developed can be used to quantitatively calculate the risk associated with a continuous spill fire.

Key words: Spill fires; Maximum spread area; Steady burning area; Risk assessment; Large-scale experiments.

\section{Nomenclature}

\begin{tabular}{|c|c|}
\hline$A_{t}$ & Upper surface area of leakage tank, $\mathrm{m}^{2}$ \\
\hline$a$ & Absorption coefficient, $\mathrm{m}^{-1}$ \\
\hline$F$ & View factor \\
\hline$\triangle H_{c}$ & Net heat of combustion, $\mathrm{kJ} / \mathrm{kg}$ \\
\hline$H$ & Vertical distance from upper surface to leakage position, $\mathrm{m}$ \\
\hline$g$ & Gravitational acceleration, $9.8 \mathrm{~m} / \mathrm{s}^{2}$ \\
\hline$L$ & Spread length, m \\
\hline$P$ & Pressure, pa \\
\hline$w_{\infty}, w_{\text {spill }}, w_{\text {pool }}$ & Maximum, spill fire, and pool fire regression rates, respectively, \\
\hline & $\mathrm{m} / \mathrm{s}$ \\
\hline$S$ & Burning area, $\mathrm{m}^{2}$ \\
\hline$t, t_{e f f}, t_{r}, t_{v}$ & Spread, exposure, reaction, and evacuated time, respectively, s \\
\hline$K$ & Spread coefficient, 1.414 \\
\hline
\end{tabular}


Spread radius, $\mathrm{m}$

$\begin{array}{ll}h, h_{\text {min }} & \text { Thickness of fuel layer, and minimum thickness, respectively, m } \\ \dot{Q} & \text { Heat release rate, } \mathrm{kW} \\ q_{\text {out }}, q_{\text {back }} & \text { Heat loss of liquid layer, and heat feedback, respectively, } \mathrm{kW} / \mathrm{m}^{2} \\ k & \text { Heat conductivity, } \mathrm{W} /(\mathrm{m} \cdot \mathrm{K}) \\ \text { Greek symbols } & \\ \sigma_{f} & \text { Surface tension, } \mathrm{mN} / \mathrm{m} \\ \rho & \text { Fuel density, } \mathrm{kg} / \mathrm{m}^{3} \\ \varphi & \text { Contact angle between the oil and soil solids } \\ k \beta & \text { Attenuation coefficient } \\ \tau & \text { Atmospheric transmissivity } \\ \eta_{\text {rad }} & \text { Fraction part by radiation }\end{array}$

\section{Introduction}

Overflows and leakages from storage tanks and pipelines carrying petroleum products occur frequently [1]. When such spills are ignited they easily turn into liquid fires, thereby posing a great threat to nearby reactors, pipelines and storage vessels, potentially triggering explosions, fires, and toxic releases [2]. The consequences of spill fires are usually serious because the influence area increases significantly due to the spread behaviour of the liquid layer [3]. The leakage and subsequent spill fire that occurred on June16th, 2010 of Dalian (Chinese city) is a representative example. In that particular accident, the valve that was used to isolate the leaking tank could not 
be closed in a timely manner, causing two explosions as a result of the spill fire [4]. Therefore, it is important to analyse the spread process as well as quantitatively assess the risk of continuous spill fires.

Quantitative risk assessment (QRA) is frequently used in fire hazard analysis [5-8]. Failure frequency, fire model, and consequence analysis (the probability of fatalities) are the key steps in the framework $[5,8]$. By combining these three components, risk distribution can be determined for industrial parks [8]. In this process, the pool fire model has been widely used with the QRA method to analyse different scenarios such as tunnel fires [9], compartment fires [10], and spill fires [11]. For example, Fay used the burning rate of pool fires to calculate the consumption during burning and assess the spill fire hazard [11]. However, it is hard to create a thick fuel fire (pool fire), with the thickness being usually less than $2-3 \mathrm{~mm}$ in industrial fires in reality [12]. Moreover, it is well known that the burning rate depends on the fuel thickness, for thin layer burning [13-15]. In the 1990s, Gottuk et al conducted a series of spill fire experiments using JP-8 and JP-5, with the burning rate of spill fires being one-fifth that of pool fires [3]. More recently, Mealy and Benfer performed experiments with continuous spill fires, finding that the burning rate was less than that of pool fires, while being related to fuel depth, supply duration, and substrate [13]. In addition, Li and Ingason conducted large-scale spill fire tests, suggesting that the burning rate of gasoline is one-third to two-fifths that in deep pool fires [12]. As a result, it is inappropriate to use the burning rate of pool fires in QRA method for spill fires, because the higher consumption during burning results directly from the smaller 
spread area during spreading. On the other hand, some causes for the decrease in burning rate have not been revealed, as the detailed spread process has not been clearly described for continuous spill fires in the above-mentioned studies. Hissong applied a "turbulence factor" to calculate heat convection, obtaining a heat transfer coefficient to calculate evaporation rate [16]. However, he did not consider the ignited condition.

Therefore, the goal of this study is to apply the QRA method to assess the risk of continuous spill fires. The entire spread behaviour is analysed based on previous experiments, with the introduction of key parameters including 'maximum spread area' and 'steady burning area'. In combination with the consequence model, the distribution of death probability is obtained. Some experimental data from large-scale experiments conducted on both a water surface and a fireproof glass sheet were used to verify the accuracy of the QRA model.

\section{Primary analysis and assessment procedure}

The risk of thermal hazards is directly related to the open fire contact area and the radiative flux for free-boundary fires $[3,13]$. In our previous study, heptane, gasoline, and JP-5 were used to study spread behaviours for a continuous leak [14-15]. The process was divided into three main phases: spread burning, shrink burning, and quasi-steady burning [14-15]. The two key points related to risk assessment are summarized as: 1) Open fire contact area (maximum spread area) and 2) Radiation hazard, caused by quasi-steady burning due to a longer duration. Therefore, maximum burning area and steady burning area were introduced in the QRA method as shown in 
Fig. 1.

As seen in Fig. 1, the risk assessment procedure is divided into three main parts: 1) leakage analysis, 2) spill fire analysis, and 3) consequence analysis. In the first part, leakage frequency and leakage rate are estimated. The maximum spread area and steady burning area are determined in the second part. In the third part, the vulnerability model is used to calculate the probability of fatalities.

\section{Procedure for assessing spill fire risk}

\subsection{Leakage analysis}

\subsubsection{Leakage frequency analysis}

The leakage frequency is the leakage probability per year for equipment. Since storage tanks and pipelines are often used in the transportation and storage of liquid fuels [1], leakages in these two scenarios are considered. A schematic diagram for such an incident is given in Fig. 2. The leakage frequency of equipment is usually calculated from the historical accidental data. At present, the leakage form is categorized based on rupture size and leakage time. The simple categorisation and the failure frequency of tanks and pipelines are shown in Tables 1 and 2, respectively (based on data in Shebeko et al [17]).

Leakage frequency data for different types of containers, including stationary atmospheric tanks, road tanks, ship tanks, pipelines, and pumps, can also be found in the 'purple books' [5].

\subsubsection{Calculation of leakage rate}

The leakage rate for atmospheric tanks can be expressed as given in Fay [11]: 


$$
Q=\frac{d\left(A_{t} h\right)}{d t}=A_{s} \sqrt{\rho_{f} g H}
$$

The leakage rate for pipelines is given in the TNO Purple Book [5]:

$$
Q=A_{s} \sqrt{\frac{2 P}{\rho_{f}}}
$$

For simplicity, the leakage rate can be considered as remaining constant for a short time under small leakage conditions in practical applications [5].

On the other hand, the burning area and the burning rate change for long-duration burning. According to the balance between discharge rate and burning consumption, the leakage rate can be expressed as:

$$
Q=w_{\text {pool }} S_{\text {quasi }}
$$

The regression rate equals that of pool fires because the heat loss of fuel layer is ignored during this phase $[3,13]$.

3.2. Spill fire analysis

\subsubsection{Spread model}

Based on the steady state Bernoulli equation, Fay provided a widely used spread model for the approximate spread on water $[11,18]$.

$$
\begin{gathered}
v=\frac{d r}{d t}=K \sqrt{\Delta g h} \\
\Delta g=g \frac{\rho_{w}-\rho_{f}}{\rho_{w}}
\end{gathered}
$$

The average thickness of the spread layer, $h$, can be expressed as:

$$
h=\frac{Q t}{\pi r^{2}}
$$

The PHAST (Software) sub-model for continuous spread is used to stimulate the fuel spread on land [19]: 


$$
\begin{gathered}
v=\frac{d r}{d t}=k \sqrt{g\left(h-h_{\text {min }}\right)} \\
h_{\min }=\sqrt{\frac{2 \sigma(1-\cos (\varphi))}{\rho_{f} g}}
\end{gathered}
$$

The spread burning area achieves the maximum value when the fuel thickness becomes equal to the minimum fuel thickness.

\subsubsection{Spill fire model}

In spill fires, the total volume that is used in spreading is equal to the leakage rate minus the consumption during burning. In this case, Eq. 6 can be expressed as follows:

$$
h=\frac{Q t-\int_{0}^{t} w_{\text {spill }} S(t) d t}{\pi r^{2}(t)}
$$

The regression rate of pool fires can be expressed as shown in Eq. 10 [20-21]. The heat loss of the fuel layer is the main reason behind the decrease in burning rate compared to pool fires [12-15]. Therefore, the burning rate of spill fires can be calculated with some modifications to the burning rate of pool fires.

$$
\begin{aligned}
w_{\text {pool }} & =w_{\infty}\left(1-e^{-2 k \beta r}\right) \\
w_{\text {spill }} & =C_{\delta} w_{\infty}\left(1-e^{-2 k \beta r}\right) \\
C_{\delta} & =1-q_{\text {out }} / q_{\text {fback }}
\end{aligned}
$$

These values are provided by Babrauskas [20] and Ditch $\left(\mathrm{kW} / \mathrm{m}^{2}\right)$ [21]. The heat loss $\left(q_{\text {out }}\right)$ of the fuel layer is the main reason for the decrease in burning rate. The heat loss of the liquid layer can be expressed as:

$$
q_{\text {out }}=\left.k \frac{\partial T}{\partial x}\right|_{x=h}+q_{\text {fback }}\left(1-e^{-a h}\right)
$$

The detailed calculation process for heat loss has been provided in previous studies 
$[22,23]$. The burning rate during fuel spread can be calculated according to Equations $1-13$.

For long-duration burning, the burning rate of spill fires (in quasi-steady burning) is equal to that of pool fires because the heat loss from the fuel layer can be ignored [12]. As a result, Eq. 3 can be used to calculate the steady burning area.

\subsection{Thermal radiation analysis}

The solid flame model is a popular method to estimate the heat flux in liquid fire accidents [5, 8, 11], as shown in Fig. 3.

The correlation used to quantify the heat flux:

$$
q=E F_{1,2} \tau
$$

The average emissive power of the flame is given by Muñoz et al [24]:

$$
E=\frac{\eta_{r a d} \rho \dot{w} \Delta H_{c}}{1+4 H / D}
$$

The flame height of an axisymmetric pool fire is expressed as shown in Eq. (16) [25], while it is as shown in Eq. (17) for a rectangular fire [26].

$$
\text { Square: } H=0.235 \dot{Q}^{2 / 5}-1.02 D
$$

$$
\text { Rectangular: } H=0.035(\dot{Q} / L)^{2 / 3} \text { (Length/width>3) }
$$

The view factor is a geometric parameter that can be expressed as follows according to the definition of view factor [27]:

$$
F_{12}=F_{A_{1} \rightarrow A_{2}}=\frac{1}{A_{1}} \int_{A_{2}} \int_{A_{1}} \frac{\cos \left(\theta_{1}\right) \cos \left(\theta_{2}\right)}{\pi r^{2}} d A_{1} d A_{2}
$$

Thermal radiation distribution can be obtained by Equations 15-18.

\subsection{Consequence analysis}

In this section, the probability of fatalities is used to express risk level. A 
cumulative expression to express human responses to thermal radiation is based on the normal Gaussian probability distribution function [6, 28].

$$
P_{\text {dead }}=\frac{1}{\sigma \sqrt{2 \pi}} \int_{-\infty}^{Y-5} e^{-u^{2} / 2} d u
$$

where $P_{\text {dead }}$ is the probability of fatality $(0 \leqslant P \leqslant 1)$ and $Y$ is a probit that can be estimated by the following equation [28]:

$$
Y=-14.9+2.56 \ln \left(10^{-4} \times q^{1.33} t_{\text {eff }}\right)
$$

Exposure time refers to the time to reach a safe place $\left(1 \mathrm{~kW} / \mathrm{m}^{2}\right)$ in Pietersen [29] and can be expressed as follows:

$$
t_{\text {eff }}=t_{r}+\frac{3}{5} \times \frac{x}{u}\left[1-\left(1+\frac{u}{x} \times t_{v}\right)^{-5 / 3}\right]
$$

In accidental scenarios, it is obvious that the personal risk is closely related to the position at beginning of evacuation and practical topography of spread region. The evacuation route considering the spread process is complicated and should be further studied in spill fires.

\section{Validation of the method}

In order to validate this method, two large-scale experiments were conducted separately on water and fireproof glass. Fig. 4 shows the schematic diagram of the experimental apparatus for spill fires on a water layer and a fireproof glass layer.

The flame can encompass the entire fuel surface instantaneously when the flash point is lower than the ambient temperature [30]. Hence, the rate of the spread of the flame front can be considered the spread rate of the fuel layer. The height and the spread length, during the fuel spread process, were captured with a digital camera. The processing method is based on the analysis of the red, blue, and green (RGB) values of every pixel, a detailed explanation of which can be found in Li et al [14]. 
Fig. 5 shows a comparison between the actual flame and the processing result.

In the experiments, heptane was selected as the liquid spread fuel. The fuel spill was ignited immediately after discharge, as specified in Table 3. Each experiment was repeated three times to ensure repeatability and increase the accuracy of the results.

\subsection{Validation of the spread model}

The maximum spread area, as a core parameter, is calculated based on Equations 114. Fig. 6 compares the values predicted by the method to the experimental values.

As seen in Fig. 6, there is good agreement between the experimental data and the predicted data calculated using our method. The maximum relative deviation and the average relative deviation on the water layer were approximately 0.08 and 0.12 , respectively. These deviations were 0.089 and 0.144 respectively on the fireproof glass sheet. In Test 4, the deviation was relatively large because the length of the rectangular trench was limited, while the actual fuel spread length was more than $7 \mathrm{~m}$. In this scenario, the resistance of water cannot be ignored. In Test 8 , some areas of the fuel layer started to boil. The friction between the glass and fuel decreased due to the numerous bubbles, which has been previously explained in detail [15].

The assessment of maximum burning area is the most important step in QRA for spill fires. The detailed process for the calculation of burning rate for spill fires has been provided in our previous studies [22, 23]. Table 4 provides a comparison between the calculated maximum burning area and the experimental area.

In Table 4, it is obvious that the deviation by spill fire model is smaller than that by pool fire model in the spread process. The maximum error between the experimental 
values and calculated values is less than $14.78 \%$ and the spill fire model can be used in the engineering field.

\subsection{Validation of heat flux}

The measured experimental heat flux data were compared with the calculated values. Fig. 7 shows the comparison between the calculated values and the experimental values for spill fires on water and fireproof glass.

Fig. 7 shows that both the predicted heat flux values and the measured values, increased with the flame spread. Meanwhile, the number of measured heat flux values close to the predicted values and relative error is less than $20 \%$. Therefore, the model provides an acceptable result, which means it can be used in the engineering field. During the measuring process, flame fluctuation and some simple assumptions, including flame shape and emissive power, lead to this deviation of the predicted values from the experimental values [24].

\section{Application of the method}

The flame is considered to be a rectangular. The evacuation direction keeps away from the centre of fire source. Fig. 8 shows the distribution of the probability of fatality for different burning durations.

From Fig. 8 it can be seen that the higher risk area enlarges quickly during the initial spread ( $\mathrm{T}<80 \mathrm{~s}$ ), after which the risk distribution gradually tends to stabilize in accordance with the spread behaviours. This observation suggests that the initial phase of a spill fire accident is highly dangerous, especially when conditions are not clear. In addition, the risk value distribution is sensitive to the spread direction, rather 
than obviously changing vertically. This suggests that it is critical to select a proper position from which to fight spill fires, especially when using a liquid extinguishing agent.

In the experiments, the spread layer was confined in the rectangular trench and the calculated death probability obviously depended on the equipment. Therefore, considering spread topography and environment conditions are critical to eventually determine evacuation route in accidental scenarios.

\section{Conclusion}

The QRA procedure was used to assess the risk of spill fires, and both the spread and burning process were considered. Based on recent results and large-scale experiments, we can conclude that:

(1) The methodology successfully introduced a way to use the maximum spread area and steady burning area to characterize the risk associated with spill fire. This model enabled the estimation of the dynamic risk variation of spill fires.

(2) The burning rate was modified in the calculation by considering the heat loss of the spread layer. The burning consumption during fuel spread was calculated by the modified burning rate model.

(3) The rapid enlargement of the burning area at the spread burning phase results from a higher risk. It is recommended that spill fires should not be responded to during the initial spread process.

The method enables the calculation of dynamic individual risk. However, the topography obviously influences how the fuel spreads. Spill fire experiments on 
sloped surfaces will be conducted in the near future.

\section{Acknowledgements}

This work was supported by the Ministry of Science and Technology of the People's Republic of China [grant numbers 2016YFC0802501 and 2015BAK12B01], the State Key Laboratory of Safety and Control for Chemicals, and Tsinghua Fudaoyuan Research Fund.

\section{References}

[1] M. Hussein, M. Jin, J.W. Weaver, Development and verification of a screening model for surface spreading of petroleum, J. Contam. Hydrol. 57 (2002)281-302.

[2] F.I. Khan, S.A. Abbasi, An assessment of the likelihood of occurrence, and the damage potential of domino effect (chain of accidents) in a typical cluster of industries, J. Loss Prev. Process Ind. 14 (2001) 283-306.

[3] D.T. Gottuk, D.A. White, Liquid Fuel Fires, The SFPE Handbook of Fire Protection Engineering (5th ed.), Morgan J. H. (ed.), Springer, 2015

[4] S. Guo, M. Peng, J. Ruan, W. Wan, Cause analysis of the fire and explosion during crude oil desulfurization in China, J. Loss Prev. Process Ind. 26 (2013) 961-967.

[5] TNO Purple Book, Guideline for Quantitative Risk Assessment, Committee for the Prevention of Disasters, Netherlands, 1999.

[6] V. Cozzani, R. Bandini, C. Basta, M. Christou, Application of land-use planning criteria for the control of major accident hazards: A case-study, J. Hazard. Mater. 136 
(2006) 170-180.

[7] M.D. Christou, A. Amendola, M. Smeder, The control of major accident hazards: the land-use planning issue, J. Hazard. Mater. 65 (1999) 151-178.

[8] R. Pula, F. I. Khan, B. Veitch, et al, Revised fire consequence models for offshore quantitative risk assessment, J. Loss Prev. Process Ind. 18(2005):443-454.

[9] P. Zhang, C. Liu, X. Tang, et al, The thermal criteria on rubber ignition in flashover fires under longitudinal ventilation surroundings, Appl. Therm. Eng. 103 (2016):1408-1415.

[10] J. Ji, M. Li, Z. H. Gao, et al, Experimental investigation of combustion characteristics under different ventilation conditions in a compartment connected to a stairwell, Appl. Therm. Eng. 101(2016):390-401.

[11] J.A. Fay, Model of spills and fires from LNG and oil tankers, J. Hazard. Mater. 96 (2003) 171-188.

[12] H. Ingason, Y. Z. Li. Spilled liquid fires in tunnels. Fire Safety J. 2017.

[13] C. Mealy, M. Benfer, G. Dan, Liquid Fuel Spill Fire Dynamics, Fire Technol. 50 (2014) 419-436.

[14] Y. Li, H. Huang, J. Zhang, C. Jiang, Large-scale experimental study on the spread and burning behavior of continuous liquid fuel spill fires on water, J. Fire Sci. 32 (2014) 391-405.

[15] J. Zhao, Q. Liu, H. Huang, R. Yang, H. Zhang, Experiments investigating fuel spread behaviors for continuous spill fires on fireproof glass. J. Fire Sci. 35 (2017) 80-95. 
[16] D. W. Hissong, Keys to modeling LNG spills on water, J. Hazard. Mater. 140 (2007) 465-477.

[17] Y.N. Shebeko, I.A. Bolodian, V.P. Molchanov, Y.I. Deshevih, D.M. Gordienko, I.M. Smolin, D.S. Kirillov, Fire and explosion risk assessment for large-scale oil export terminal, J. Loss Prev. Process Ind. 20 (2007) 651-658.

[18] A. S. Esteves, J. A. R. Parise, Mathematical modeling of cryogenic spills onto quiescent sea waters followed by pool fires of liquefied natural gas (LNG), Appl. Therm. Eng. 59(1) (2013): 587-598.

[19] H.W.M. Witlox, Model for pool Spreading, Evaporation and Solution on Land and Water (PVAP) -Theory Manual, Consequence modelling documentation (PHAST Technical Reference), 2000.

[20] V. Babrauskas, Estimating large pool fire burning rates, Fire Technol. 19(1983)251-261.

[21] B.D. Ditch, J.L.D. Ris, T.K. Blanchat, M. Chaos, R.G. Bill Jr, S.B. Dorofeev, Pool fires-An empirical correlation, Combust. Flame 160 (2013) 2964-2974.

[22] J. Zhao, H. Huang, Y. Li, B. Su, N. Zhang, Experimental and modeling study of the behavior of a large-scale spill fire on a water layer. J. Loss Prev. Process Ind. 43 (2016) 514-520.

[23] J. Zhao, H. Huang, G. Jomaas, et al, Spread and burning behavior of continuous spill fires, Fire Safety J. 2017.

[24] M. Muñoz, E. Planas, F. Ferrero, J. Casal, Predicting the emissive power of hydrocarbon pool fires, J. Hazard. Mater. 144 (2007) 725-729.

[25] Y. Hasemi, M. Nishihata, Fuel shape effect on the deterministic properties of 
turbulent diffusion flames, Proc. Fire Saf. Sci. 2 (1988) 275-284.

[26] G. Heskestad, Fire Plumes, SFPE Handbook of Fire Protection Engineering (second ed.), National Fire Protection Association, Quincy, MA, 1995.

[27] F.P. Incropera, D.P. DeWitt, T.L. Bergman, A.S. Lavine, Fundamentals of heat and mass transfer, 6th edition, John Wiley\&Sons Inc., New York, 2002.

[28] V. Cozzani, G. Gubinelli, G. Antonioni, G. Spadoni, S. Zanelli, The assessment of risk caused by domino effect in quantitative area risk analysis, J. Hazard. Mater. 127 (2005) 14-30.

[29] C. M. Pietersen, Consequences of accidental releases of hazardous material, J. Loss Prev. Process Ind. 3(1) (1990): 136-141.

[30] I. Glassman, F. L. Dryer, Flame spreading across liquid fuels, Fire Safety J. 3 (1981) 123-138. 


\section{Table captions}

Table 1: Failure frequencies of different forms of leakage for tanks and pumps

Table 2: Failure frequencies of different forms of leakage for pipelines

Table 3: Specification of the test conditions

Table 4: Comparison between the calculated and experimental maximum spread area 


\section{Figure captions}

Figure 1: The quantitative risk assessment procedure for spill fires.

Figure 2: Schematic diagram of the leakage process: (a) a tank rupture and (b) a pipeline rupture.

Figure 3: "Solid flame” radiation model.

Figure 4: Schematic diagram of the experimental apparatus for spill fires: (a) on a water surface and (b) on a fireproof glass sheet.

Figure 5: Comparison between the actual flame and the processing result.

Figure 6: Comparison between the results of the predicted values and the experimental values.

Figure 7: Comparison between the calculated and experimental values for spill fires (a) on water surface and (b) on a glass sheet.

Figure 8: Distribution of probability of fatality under different burning durations for Test 4. 
Table 1. Failure frequencies of different forms of leakage for tanks and pumps

\begin{tabular}{|c|c|c|c|c|}
\hline $\begin{array}{c}\text { Type of } \\
\text { equipment }\end{array}$ & Initiating event & $\begin{array}{c}\text { Diameter of } \\
\text { discharge } \\
(\mathrm{mm})\end{array}$ & Description & $\begin{array}{l}\text { Frequency } \\
\left(\text { year }^{-1}\right)\end{array}$ \\
\hline \multirow{4}{*}{$\begin{array}{l}\text { Tank with a } \\
\text { floating roof }\end{array}$} & Discharge & 12.5 & \multirow{4}{*}{$\begin{array}{l}\text { Long time } \\
\text { release }\end{array}$} & $5.8 \times 10^{-5}$ \\
\hline & through the hole & 25 & & $2.3 \times 10^{-5}$ \\
\hline & in & 50 & & $5.8 \times 10^{-6}$ \\
\hline & the tank's wall & 100 & & $2.9 \times 10^{-6}$ \\
\hline \multirow{2}{*}{ Pump } & Formation of a & 12.5 & \multirow{2}{*}{$\begin{array}{l}\text { Long time } \\
\text { release }\end{array}$} & $1.0 \times 10^{-4}$ \\
\hline & hole & 25 & & $3.1 \times 10^{-7}$ \\
\hline \multirow{4}{*}{$\begin{array}{c}\text { Vessels } \\
\text { operating at } \\
\text { overpressure } \\
\text { and containing } \\
\text { liquid phase }\end{array}$} & & 12.5 & \multirow{4}{*}{$\begin{array}{l}\text { Long time } \\
\text { release }\end{array}$} & $5.1 \times 10^{-6}$ \\
\hline & Hole under a & 25 & & $2.2 \times 10^{-6}$ \\
\hline & liquid level & 50 & & $7.0 \times 10^{-7}$ \\
\hline & & 100 & & $1.9 \times 10^{-7}$ \\
\hline
\end{tabular}

Table 2. Failure frequencies of different forms of leakage for pipelines

\begin{tabular}{cccc}
\hline \multirow{2}{*}{$\begin{array}{c}\text { Diameter of a } \\
\text { pipeline }(\mathrm{mm})\end{array}$} & \multicolumn{3}{c}{ Frequency of failure $\left(\mathrm{m}^{-1}\right.$ year $\left.^{-1}\right)$ for } \\
\cline { 2 - 4 } 50 & Small hole & Medium hole & Large hole \\
\hline $5.7 \times 10^{-5}$ & $2.4 \times 10^{-6}$ & $9.4 \times 10^{-7}$ \\
100 & $2.8 \times 10^{-6}$ & $1.2 \times 10^{-6}$ & $4.7 \times 10^{-7}$ \\
150 & $1.9 \times 10^{-6}$ & $7.9 \times 10^{-7}$ & $3.1 \times 10^{-7}$ \\
250 & $1.1 \times 10^{-6}$ & $4.7 \times 10^{-7}$ & $1.9 \times 10^{-7}$ \\
600 & $4.7 \times 10^{-7}$ & $2.0 \times 10^{-7}$ & $7.9 \times 10^{-8}$ \\
900 & $3.1 \times 10^{-7}$ & $1.3 \times 10^{-7}$ & $5.2 \times 10^{-8}$ \\
1200 & $2.4 \times 10^{-7}$ & $9.8 \times 10^{-7}$ & $3.9 \times 10^{-8}$ \\
\hline
\end{tabular}


Table 3. Specification of the test conditions

\begin{tabular}{cccc}
\hline $\begin{array}{c}\text { Test } \\
\text { Number }\end{array}$ & $\begin{array}{c}\text { Discharge } \\
\text { Rate (L/min) }\end{array}$ & Substrate & $\begin{array}{c}\text { Discharge } \\
\text { Time (s) }\end{array}$ \\
\hline 1 & 10 & Water & 210 \\
2 & 20 & Water & 105 \\
3 & 30 & Water & 120 \\
4 & 40 & Water & 52.5 \\
5 & 0.93 & Fire proof glass & 216 \\
6 & 2.05 & Fire proof glass & 212 \\
7 & 4.39 & Fire proof glass & 213 \\
8 & 6.82 & Fire proof glass & 208 \\
\hline
\end{tabular}

Table 4. Comparison between the calculated and experimental maximum spread

area

\begin{tabular}{cccccc}
\hline $\begin{array}{c}\text { Test } \\
\text { Number }\end{array}$ & $\begin{array}{c}\text { Experimental } \\
\text { Value }(\mathrm{m})\end{array}$ & $\begin{array}{c}\text { Pool Fire } \\
\text { Model }(\mathrm{m})\end{array}$ & $\begin{array}{c}\text { Relative } \\
\text { Error }\end{array}$ & $\begin{array}{c}\text { Spill Fire } \\
\text { Model }(\mathrm{m})\end{array}$ & $\begin{array}{c}\text { Relative } \\
\text { Error }\end{array}$ \\
\hline 1 & 2.84 & 1.87 & $34.15 \%$ & 2.42 & $14.78 \%$ \\
2 & 4.02 & 3.21 & $20.74 \%$ & 4.09 & $1.75 \%$ \\
3 & 5.78 & 4.39 & $24.05 \%$ & 5.91 & $2.25 \%$ \\
4 & 6.61 & 5.32 & $19.52 \%$ & 7.53 & $13.92 \%$ \\
5 & 1.21 & 0.93 & $23.14 \%$ & 1.07 & $11.57 \%$ \\
6 & 1.83 & 1.71 & $6.56 \%$ & 1.80 & $1.64 \%$ \\
7 & 2.83 & 2.36 & $16.61 \%$ & 2.61 & $7.76 \%$ \\
8 & 3.83 & 2.94 & $23.24 \%$ & 3.51 & $8.36 \%$ \\
\hline
\end{tabular}




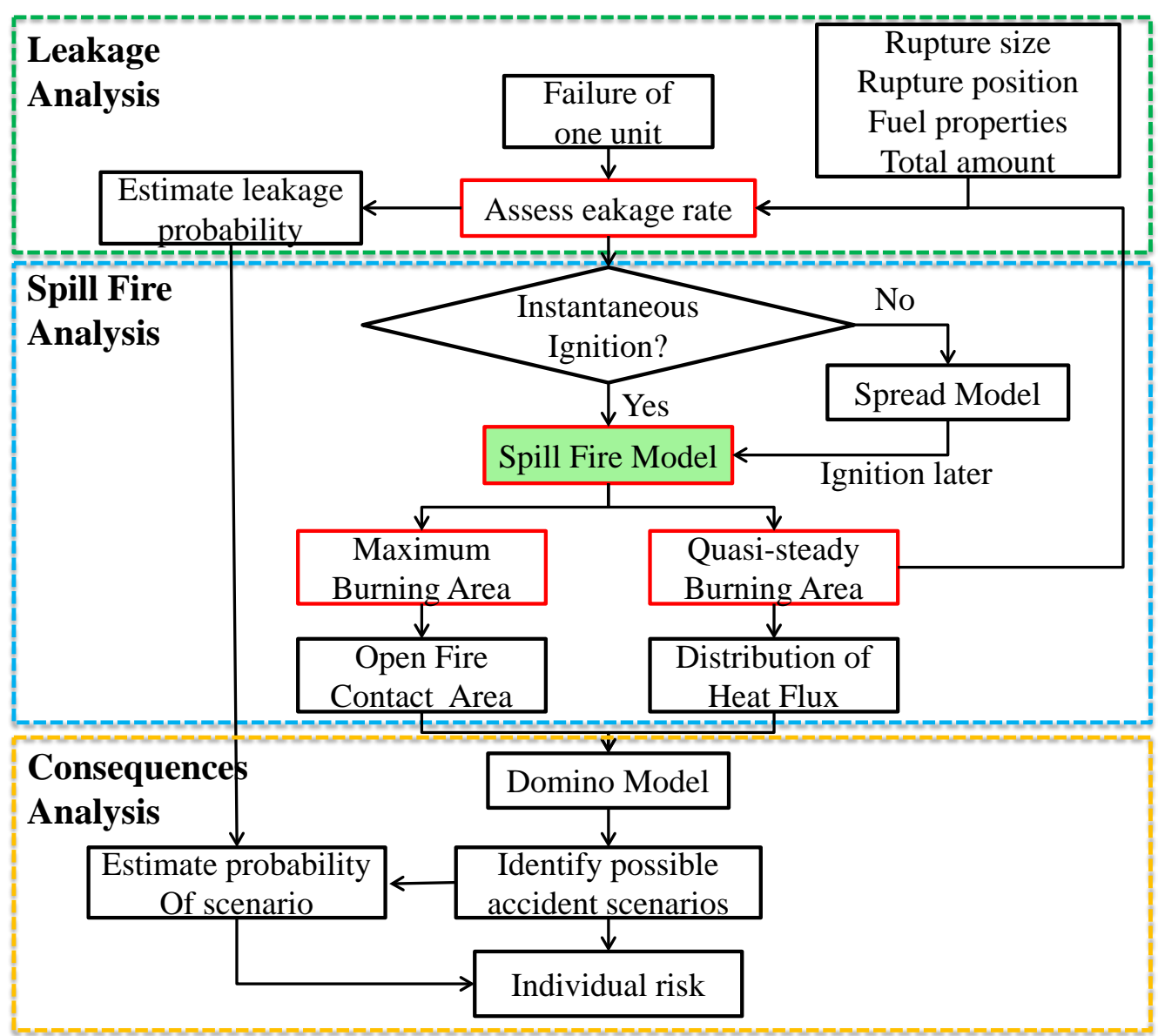

Fig. 1. Quantitative risk assessment procedure for spill fires 

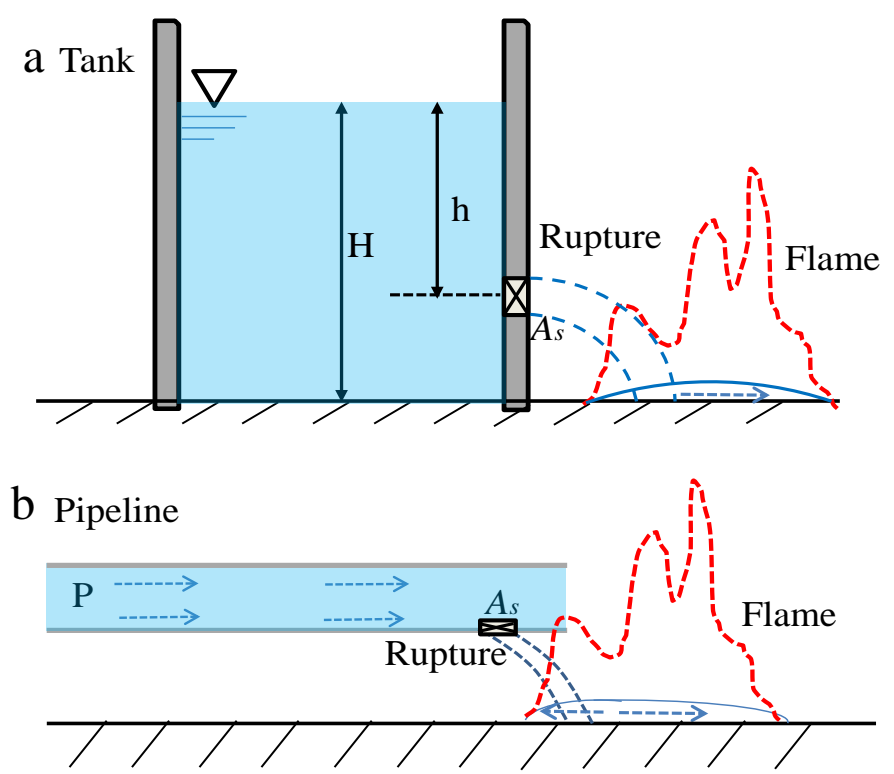

Fig. 2. Schematic diagram of the leakage process: (a) a tank rupture and (b) a pipeline rupture

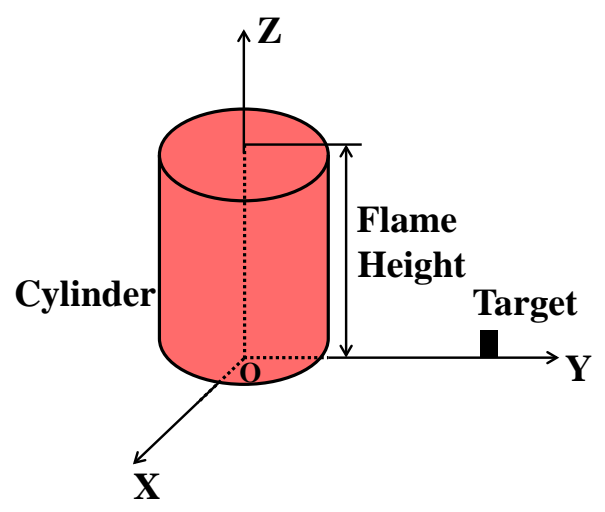

Fig. 3. "solid flame” radiation model 

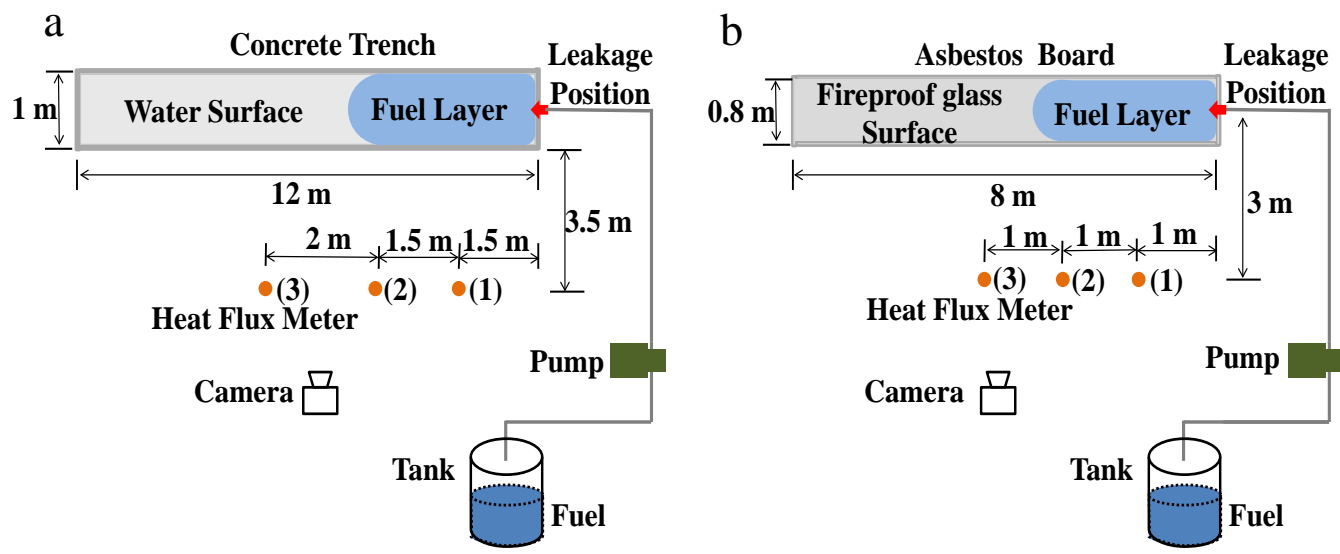

Fig. 4. Schematic of the experimental apparatus for spill fires: (a) on a water surface and (b) on a fireproof glass sheet

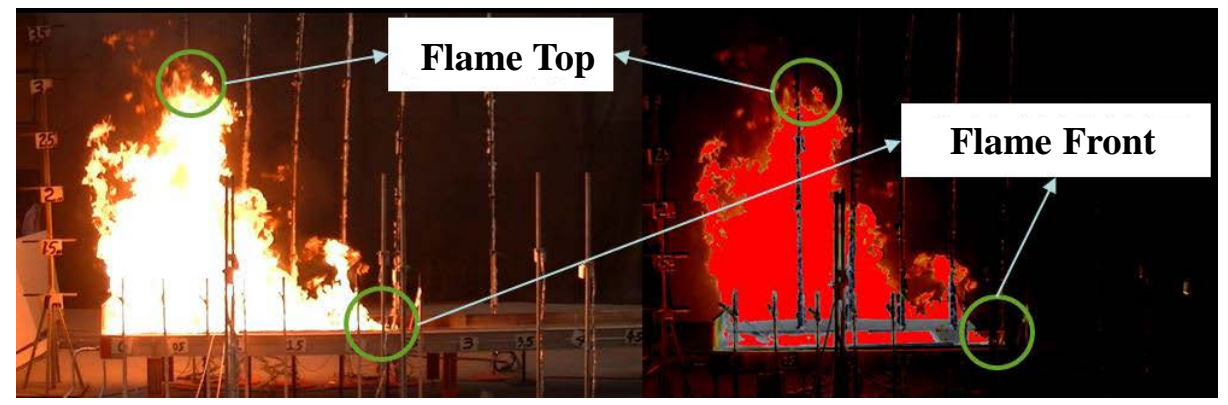

Fig. 5. Comparison between the actual flame and the processing result 


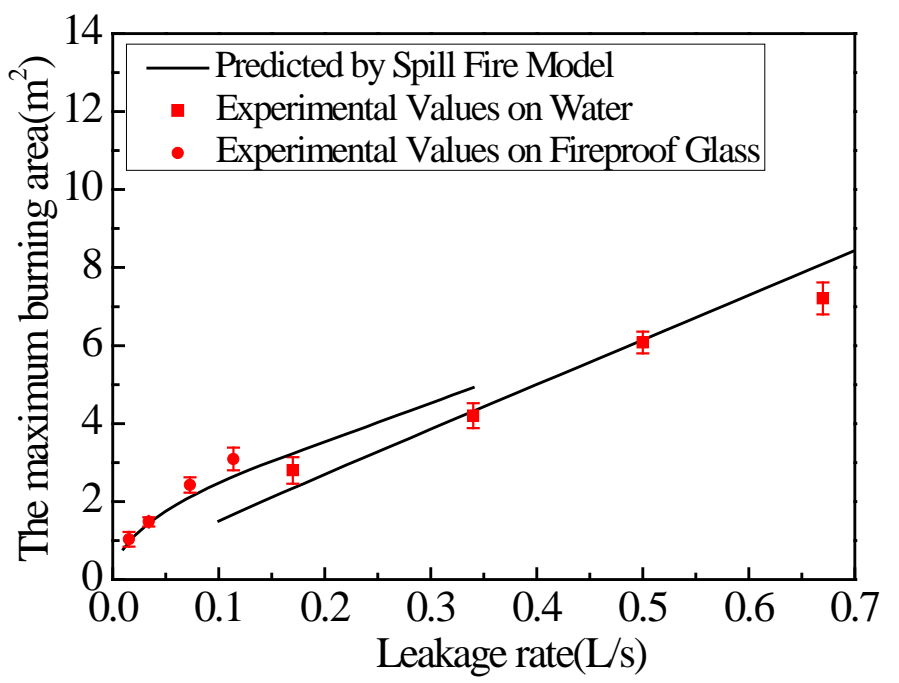

Fig. 6. Comparison between the results of the predicted values and the experimental values 

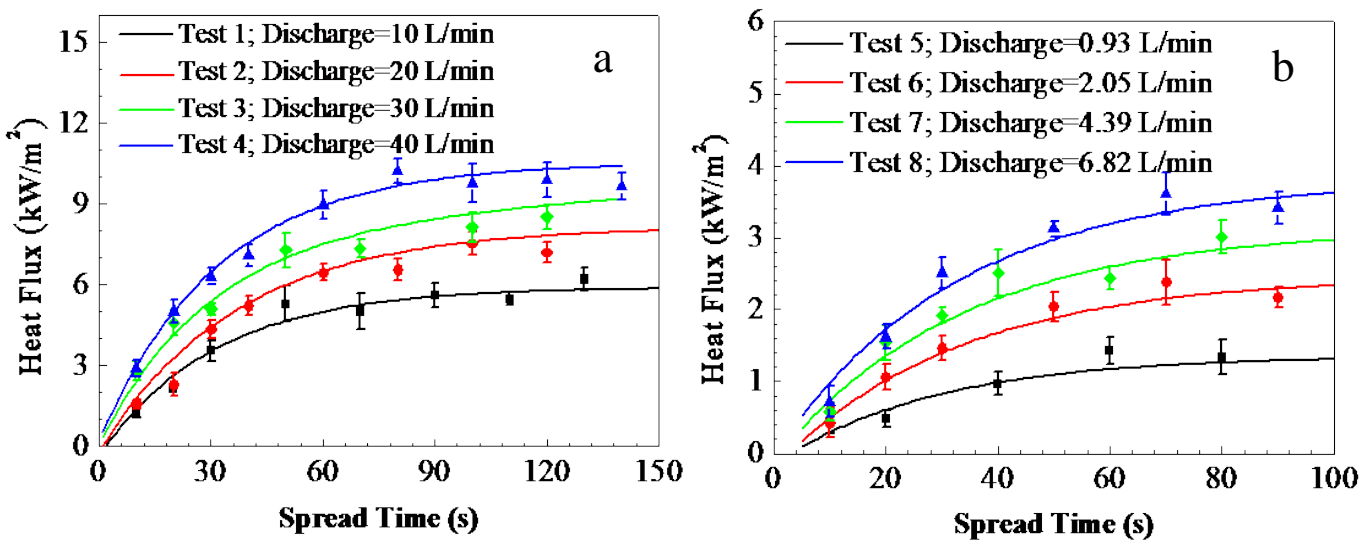

Fig. 7. Comparison between the calculated and experimental values for spill fires (a) on water surface and (b) on a glass sheet
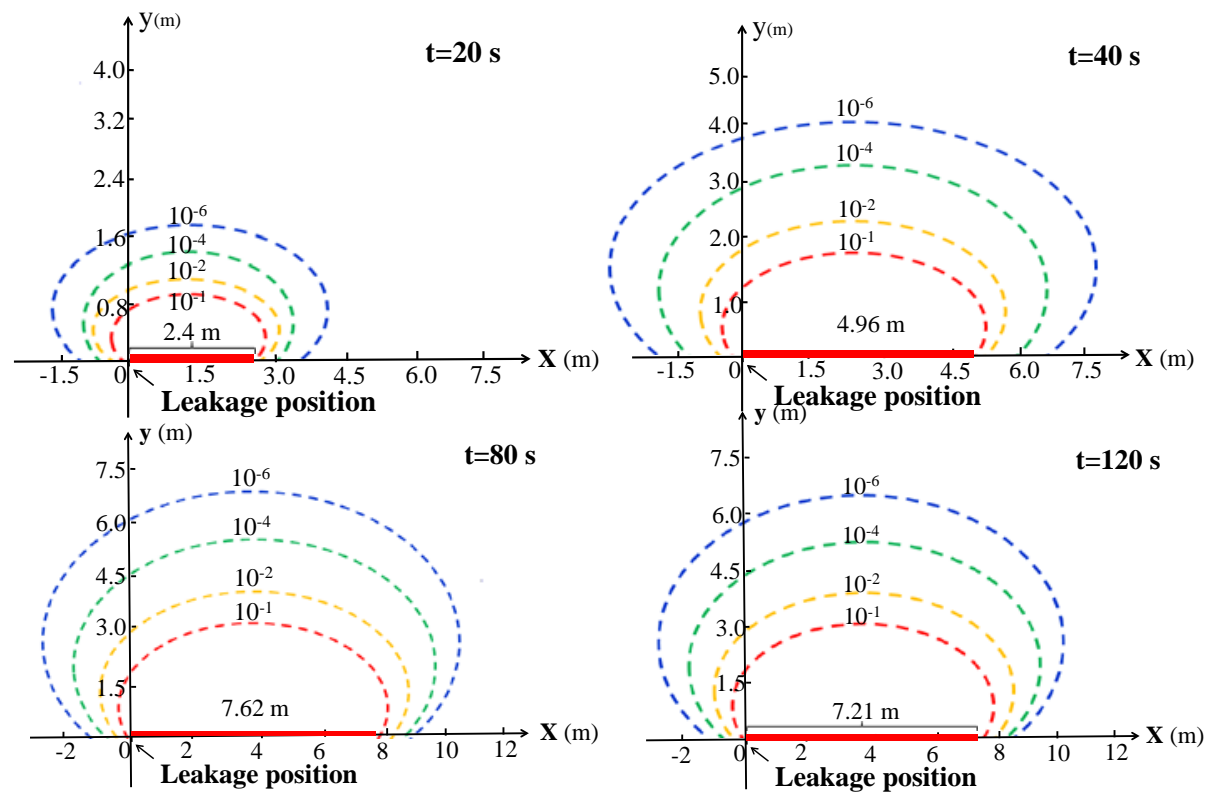

Fig. 8. Distribution of probability of fatality under different burning durations for Test 4 